\title{
Anxiety and memory
}

\author{
JACK HAYNES and JOHN GORMLY \\ Rutgers University, New Brunswick, New Jersey 08903
}

\begin{abstract}
This study investigates the relationship between the trait of anxiety and memory in a nonclinical population. Thirteen males were each rated by 30 peers for the degree to which they were characterized by the trait of anxiety. The subjects were then tested individually on the Digit Span subtest of the Wechsler Adult Intelligence Scale. The correlation between the anxiety and memory scores was $.73(p<.01)$, indicating a substantial relationship in which the more anxious subjects had better memory scores. The results are contrary to the major assumption about the relationship between anxiety and performance on the Digit Span subtest, although they are consistent with a drive theory of anxiety. Distinction must be made between the trait of anxiety and states of anxiety during testing to better understand the relationship between anxiety and memory.
\end{abstract}

Human memory is a fundamental area of investigation for experimental psychology. Since the time of Thorndike, researchers have been interested in the way personality traits influence basic behavior like memory (Thorndike, Terman, Freeman, Colvin, Pintner, Ruml, $\&$ Pressey, 1921). The large number of research studies which have attempted to relate personality characteristics to differences in performance, however, has produced marginal, inconsistent, and often insignificant results (Mischel, 1968). A major problem with these investigations, undoubtedly, was the inadequacy of the procedures for assessing personality.

Recently, Gormly and his associates (Gormly \& Edelberg, 1974; McGowan \& Gormly, in press; Gormly \& Champagne, Note 1) have conducted a series of studies that have demonstrated the validity of personality traits assessed by peer ratings when the number of raters is large (approximately 30 raters) and when the peer-raters have observed the subjects in a variety of environments. Under these conditions, as much as $50 \%$ of the variance for selected social behaviors can be accounted for by personality traits. The purpose of the present research was to reinvestigate the relationship between anxiety and memory, where memory is assessed by the Digit Span subtest of the Wechsler Adult Intelligence Scale (Wechsler, 1955). Anxiety is assessed from the ratings of 30 peer-raters who share a homelike (fraternity) environment with each subject.

\section{METHOD}

\section{Subjects}

Thirteen undergraduate males who were enrolled in Rutgers College of Rutgers University served as subjects. They were members of fraternities that were participating in a longitudinal project involving experimental research in personality.

This research was supported by a grant from the Research Council of Rutgers University and a Biomedical Research Support grant. Requests for reprints should be sent to: John Gormly, Department of Psychology, Rutgers College, Rutgers University, New Brunswick, New Jersey 08903.

\section{Procedure}

Each person was rated by 30 members of his fraternity for the degree to which he was characterized by the trait of anxiety. This trait was embedded in a list of other traits. The raters simply had to decide whether or not the person was characterized by anxiety, a dichotomous decision. A person's score for anxiety was the proportion of raters who indicated he was characterized by anxiety.

The subjects were tested individually in a psychological laboratory. They were given the procedure for memory (Digit Span) which is part of the Wechsler Adult Intelligence Scale (Wechsler, 1955). In the subtest, the subject repeats digits in the order in which they are heard and later repeats other digits in reverse order from that in which they are heard. The experimenter begins with three digits, and if the subject repeats them correctly, the sequence proceeds to four digits and eventually proceeds to as many as nine digits. If the subject answers incorrectly, he is given a second trial with the same number of digits. After failing two trials of any particular number of digits, the task is terminated.

The task is repeated beginning with a new series of three digits and proceeding to eight digits, this time the subject being required to repeat them in the reverse order from that presented. As with the digits forward, if the subject answers a series incorrectly, he is given a second trial with the same number of digits. If he fails both trials, the task is terminated. A single score is given: the number of correctly repeated digits forward plus the number of correctly repeated digits backward.

\section{RESULTS}

The mean score for this sample on the Digit Span subtest was 12.85 digits, with a standard deviation of 2.08. The correlation between anxiety and memory was substantial $(r=.73, N=13, p<.01)$. This correlation indicates that the more anxious subjects had better scores for memory. The plot of the data is given in Figure 1. As can be seen from the figure, the range of anxiety scores is quite large. The percentile norms come from 61 male undergraduates, each of whom has been rated by approximately 30 peers.

\section{DISCUSSION}

The results of this research, the positive relationship between anxiety and memory, are contrary to the major assumption 


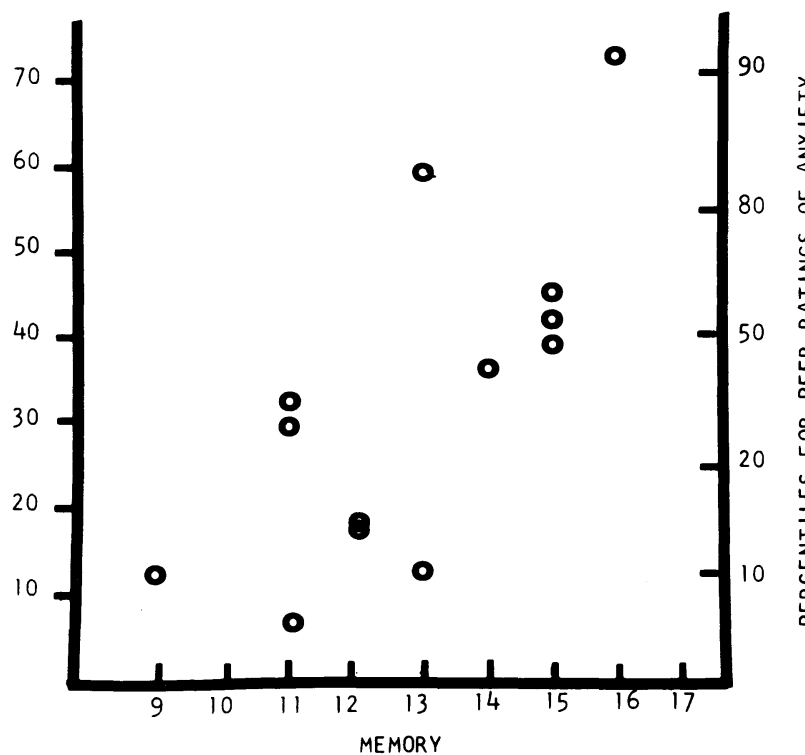

Figure 1. Plot of digit span total and anxiety score (proportion of peers characterizing subject as anxious).

about the relationship between anxiety and performance on the Digit Span subtest of the WAIS. Two empirical studies have supported the notion that anxiety interferes with performance, and they require examination. Moldawsky and Moldawsky (1952) indicated to a group of subjects that there was something unusual (and by inference, something undesirable) in their past test performance. This induced anxiety resulted in decreased performance on the Digit Span measure. Walker and Spence (1964) designed their research as a variant of the Moldawsky study and found the same phenomenon: Induced anxiety at the time of testing reduced performance on the Digit Span subtest. These studies should not be generalized to the trait of anxiety which lends itself to a drive theory interpretation. Within the ranges of a normal (nonclinical) population, anxiety can be conceptualized as emotional activation which facilitates performance. The results of this study are consistent with the drive theory of anxiety and point to the need to separate at a conceptual level the trait of anxiety and induced, state anxiety, which is more likely to interfere with performance by distracting the person from the task.

A second facet of this research is that it is contrary to the large body of research reviewed by Mischel (1968) in which personality variables were found generally to have trivial associations with different measures. It appears that improved assessment of personality characteristics warrants a reinvestigation of the hypothesis that personality traits influence performance in an important manner.

\section{REFERENCE NOTE}

1. Gormly, J. \& Champagne, B. Validity in personality trait ratings. Paper presented at the meeting of the Eastern Psychological Association, Philadelphia, Pennsylvania, April 1974.

\section{REFERENCES}

Gormly, J., \& EDelberg, W. Validity in personality trait attribution. American Psychologist, 1974, 29, 189-193.

McGowan, J., \& GoRmLY, J. Validity of personality traits: A multicriteria approach. Journal of Personality and Social Psychology, in press.

Mischel, W. Personality and assessment. New York: Wiley, 1968.

Moldawsky, S., \& Moldawsky, P. C. Digit span as an anxiety indicator. Journal of Consulting Psychology, 1952, 16, $115-118$.

Thorndike, E. L., Terman, L. M., Freeman, F. N., Colvin, S. S., Pintner, R., Ruml, B., \& Pressey, S. L. Journal of Educational Psychology, 1921, 12, 123-147.

W ALKer, R. E., \& SPEnce, J. T. Relationship between digit span and anxiety. Journal of Consulting Psychology, 1964, 28, 220-223.

WECHSLER, D. Wechsler Adult Intelligence Scale. New York: The Psychological Corporation, 1955.

(Received for publication October 18, 1976.) 